\title{
Focal Cutaneous Irradiation
}

National Cancer Institute

\section{Source}

National Cancer Institute. Focal Cutaneous Irradiation. NCI Thesaurus. Code C161507.

A procedure involving irradiation to a specific, limited area of the skin. 